\title{
Comparing the effects of nano-sized sugarcane fiber with cellulose and psyllium on hepatic cellular signaling in mice
}

This article was published in the following Dove Press journal:

International Journal of Nanomedicine

16 June 2012

Number of times this article has been viewed

\author{
Zhong Q Wang ${ }^{1,2}$ \\ Yongmei Yu ${ }^{1,2}$ \\ Xian H Zhang ${ }^{1,2}$ \\ Z Elizabeth Floyd ${ }^{3}$ \\ Anik Boudreau ${ }^{2}$ \\ Kun Lian ${ }^{4}$ \\ William T Cefalu ${ }^{1,2}$
}

'Nutrition and Diabetes Research Laboratory, ${ }^{2}$ Botanical Research

Center, ${ }^{3}$ Ubiquitin Laboratory, Pennington Biomedical Research

Center, Louisiana State University System, Baton Rouge, LA, USA; ${ }^{4}$ The Center for Energy and Environmental Studies, Southern University, Baton Rouge, LA, USA
Correspondence: Zhong Q Wang; William T Cefalu

Nutrition and Diabetes Research Laboratory, Pennington Biomedical Research Center, LSU system, 6400 Perkins Road, Baton Rouge, LA 70808, USA

Tel +l 2257630252

Fax +l 2257630274

Email wangzq@pbrc.edu; cefaluwt@ pbrc.edu
Aim: To compare the effects of dietary fibers on hepatic cellular signaling in mice.

Methods: Mice were randomly divided into four groups ( $n=9$ /group): high-fat diet (HFD) control, cellulose, psyllium, and sugarcane fiber (SCF) groups. All mice were fed a HFD with or without $10 \%$ dietary fiber (w/w) for 12 weeks. Body weight, food intake, fasting glucose, and fasting insulin levels were measured. At the end of the study, hepatic fibroblast growth factor (FGF) 21, AMP-activated protein kinase (AMPK) and insulin signaling protein content were determined.

Results: Hepatic FGF21 content was significantly lowered, but $\beta$ Klotho, fibroblast growth factor receptor 1, fibroblast growth factor receptor 3, and peroxisome proliferator-activated receptor alpha proteins were significantly increased in the SCF group compared with those in the HFD group $(P<0.01)$. SCF supplementation also significantly enhanced insulin and AMPK signaling, as well as decreased hepatic triglyceride and cholesterol in comparison with the HFD mice. The study has shown that dietary fiber, especially SCF, significantly attenuates lipid accumulation in the liver by enhancing hepatic FGF21, insulin, and AMPK signaling in mice fed a HFD.

Conclusion: This study suggests that the modulation of gastrointestinal factors by dietary fibers may play a key role in both enhancing hepatic multiple cellular signaling and reducing lipid accumulation.

Keywords: dietary fiber, FGF21, insulin signaling, AMPK, GLP-1, PI 3K

\section{Introduction}

Nonalcoholic fatty liver disease (NAFLD), characterized by excessive lipid accumulation in the liver, is a significant health problem affecting 70 million adults in the USA ( $30 \%$ of the adult population). An estimated $20 \%$ of these individuals have the most severe form of NAFLD - nonalcoholic steatohepatitis. Although the mechanisms underlying the disease development and progression are awaiting clarification, ${ }^{1}$ insulin resistance and obesity-related inflammation, among other possible genetic, dietary, and lifestyle factors, are thought to play a key role. ${ }^{2,3}$

Hormones such as insulin and glucagon have well-established roles in controlling substrate utilization and energy balance in response to nutritional status. Briefly, insulin activates the insulin receptor tyrosine kinase (IR), which phosphorylates and recruits different substrate adaptors such as the insulin receptor substrate (IRS) family of proteins. Tyrosine-phosphorylated IRS then displays binding sites for numerous signaling partners. A key action of insulin is to stimulate glucose uptake into cells by inducing translocation of the glucose transporter 4 from intracellular storage to the plasma membrane. ${ }^{4}$ Phosphatidylinositol 3 kinase (PI 3K) and protein kinase 
B (Akt) are known to play a role in glucose transporter 4 translocation. ${ }^{5}$

Fibroblast growth factors (FGFs) are a large family of polypeptide growth factors that are found in organisms ranging from nematodes to humans. In particular, hormone-like FGF19, FGF21, and FGF23 have been shown to be involved in glucose, lipid, bile acid, phosphate, and vitamin D metabolism via $\beta$ Klotho, a protein that binds FGF21 and facilitates FGF21 activation of FGF receptors (FGFRs - such as FGFR1 and FGFR3). However, the cellular mechanisms underlying their functions as metabolic regulators are still being defined. ${ }^{6}$ FGF21 has recently been identified as an important regulator of glucose and lipid metabolism in animal models. ${ }^{7,8}$ FGF21, induced in the liver in response to fasting, has been shown to increase hepatic lipid oxidation via increased gene expression of peroxisome proliferator-activated receptor $\gamma$ coactivator protein 1 alpha (PGC-1 $\alpha$ ), a key transcriptional regulator of energy homeostasis, and causes corresponding increases in fatty acid oxidation, tricarboxylic acid cycle flux, and gluconeogenesis without increasing glycogenolysis. ${ }^{9}$ FGF21 is also regulated by peroxisome proliferator-activated receptor alpha (PPAR $\alpha)$ activation, which plays a critical role in regulating metabolism during ketosis. ${ }^{9,10}$ It has been observed that transgenic mice with overexpression of FGF21 are resistant to diet-induced obesity and metabolic disturbance. ${ }^{11}$ Administration of FGF21 also enhances insulin sensitivity in insulin-resistant animals. FGF21's acute glucose-lowering and insulin sensitizing effects are potentially associated with its metabolic actions in the liver and adipose tissues. ${ }^{12}$ In diabetic animals, FGF21 improves pancreatic beta-cell function and survival by activation of extracellular signal-regulated kinase $1 / 2$ and Akt signaling pathways. ${ }^{13}$ A study has shown that FGF21 regulates energy homeostasis in adipocytes through activation of AMP-activated protein kinase (AMPK) and sirtuin 1 (SIRT1), resulting in enhanced mitochondrial oxidative function. ${ }^{14}$ Paradoxically, elevated FGF21 has also been identified as an independent risk factor related to metabolic syndrome. ${ }^{15,16}$

Dietary fiber consumption may facilitate weight loss and improve lipid profiles and glucose metabolism. ${ }^{17-19}$ However, the cellular signaling mechanisms of dietary fiber-mediated improvements in glucose and lipid metabolism remain largely unknown. Our previous study showed the various effects of dietary fibers on metabolism in a diet-induced obesity (DIO) animal. Dietary fibers incorporated into high-fat diets (HFDs) such as sugarcane fiber (SCF) and psyllium (PSY) appeared to attenuate weight gain, enhance insulin sensitivity, modulate leptin and glucagon-like peptide 1 (GLP-1) secretion, and down-regulate gastric ghrelin gene expression. ${ }^{20}$ Given the importance of insulin, FGF21, and AMPK signaling in both glucose and fatty acid metabolism, we hypothesized that dietary fiber-mediated changes in insulin sensitivity are involved in these cellular signaling pathways. Thus, using the tissues from a previously reported cohort of mice fed an HFD, ${ }^{20}$ we compared the effects of three dietary fibers on hepatic FGF21, insulin, and AMPK signaling.

\section{Materials and methods Animals}

The design of the animal study and the results for carbohydrate metabolism and body weight were previously reported. ${ }^{20} \mathrm{As}$ described, thirty-six male 4-week-old C57BL/6 mice were obtained from the Jackson Laboratory (Bar Harbor, ME). After arrival, the animals were housed one per cage with ad libitum access to rodent chow and water for a 2-week acclimation period under specific pathogen-free conditions with a 12-hour light-dark cycle. Animals were then randomly divided into four treatment groups: HFD alone, HFD containing 10\% (wt/wt) cellulose (CEL), HFD containing 10\% (w/w) PSY, and HFD containing $10 \%(\mathrm{w} / \mathrm{w}) \mathrm{SCF}$. At the end of the 12-week study, the mice were fasted overnight and then euthanized via carbon dioxide inhalation followed by decapitation at the basal condition $(n=5)$ or insulin-stimulated condition $(\mathrm{n}=4$, at 10 minutes, insulin injection at a dose of $2 \mathrm{U} / \mathrm{kg}$ body weight) for each group. Liver and other tissues were collected, quickly placed in a liquid nitrogen container, and then stored at $-80^{\circ} \mathrm{C}$ until analysis. This animal protocol was approved by the Institutional Animal Care and Use Committee of Pennington Biomedical Research Center.

\section{Sources of dietary fiber}

PSY husk powder $(>75 \%$ soluble fiber, average particle size $>100 \mu \mathrm{m}$ ) was obtained from Source Naturals (Scotts Valley, CA). CEL powder (100\% insoluble fiber, particle size $\leq 100 \mu \mathrm{m}$ ) was obtained from NutriCology (Hayward, CA). Nano-sized SCF (85\% insoluble, $70 \%$ of particles $<1 \mu \mathrm{m}$ ) was prepared by Dr Kun Lian at the Center for Advanced Microstructures and Devices at Louisiana State University. Briefly, after the sugarcane was crushed to extract the juice, a proprietary method was used to reduce the remaining components (bagasse) to nanometer-sized particles (Figure S1). This processing technology maintains the integrity of the constituents of the original bagasse as described previously. ${ }^{20}$

\section{Blood chemistry and hormone analysis}

After 4 hours of fasting, blood samples were collected from the orbital sinus of anesthetized mice at week 11 of the 
study. Plasma insulin, glucose levels, plasma triglyceride, and cholesterol concentrations were determined as previously described..$^{20,21}$ Homeostasis model assessment - insulin resistance (HOMA-IR) was calculated using the following formula: HOMA-IR $=\left[\mathrm{I}_{0}(\mu \mathrm{U} / \mathrm{mL}) \times \mathrm{G}_{0}(\mathrm{mmol} / \mathrm{L})\right] / 22.5{ }^{22}$

\section{Lipid extract from liver for triglyceride and cholesterol measurements}

Liver lipid content was determined by the Folch procedure. ${ }^{21}$ Briefly, liver tissues (about $25 \mathrm{mg}$ ) were added to five volumes of phosphate-buffered saline (PBS) (w/v), minced with scissors in an Eppendorf (Hamburg, Germany) microcentrifuge tube, and homogenized. Liver lysates were added to ten volumes of an extract solvent containing 2:1 chloroform:methanol $(\mathrm{v} / \mathrm{v})$. After vortexing, the tubes were centrifuged at $5000 \mathrm{~g}$ for 10 minutes. Aliquots of $100 \mu \mathrm{L}$ were removed from the bottom phase, transferred to a new tube, and dried under nitrogen gas. After drying, $100 \mu \mathrm{L}$ of PBS was added to the tube along with $5 \mu \mathrm{L}$ of the mixture used to measure triglyceride or cholesterol content using a tryglyceride reagent kit (Sidma-Aldrich, St Louis, MO) or a cholesterol quantitation kit (BioVision, Milpitas, CA) as per manufacturers' instructions. The results were normalized by protein concentration.

\section{Immunoblotting analysis}

Liver tissue lysates were prepared by homogenization in buffer A (25 mM 4-(2-hydroxyethyl)-1-piperazineethanesulfonic acid, pH 7.4; 1\% NP-40 (Calbiochem, Darmstadt, Germany); $137 \mathrm{mM} \mathrm{NaCl} ; 1 \mathrm{mM}$ henylmethanesulfonylfluoride; $10 \mu \mathrm{g} /$ $\mathrm{mL}$ aprotinin; $1 \mu \mathrm{g} / \mathrm{mL}$ pepstatin; $5 \mu \mathrm{g} / \mathrm{mL}$ leupeptin) using a PRO200 homogenizer (PRO Scientific Inc, Oxford, CT). The samples were centrifuged at $14000 \mathrm{~g}$ for 20 minutes at $4{ }^{\circ} \mathrm{C}$ and protein concentrations of the supernatants were determined using a protein assay kit (Bio-Rad Laboratories, Inc, Hercules, CA). Supernatants $(50 \mu \mathrm{g})$ were resolved by sodium dodecyl sulfate polyacrylamide gel electrophoresis and subjected to immunoblotting. Protein abundances were detected with antibodies against insulin receptor substrate 1

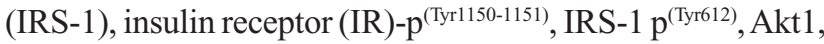
Akt1 $\mathrm{p}^{(\mathrm{ser} 473)}, \mathrm{AMPK} \alpha \mathrm{p}^{(\mathrm{Thr} 172)}$, AMPK $\alpha 1$, AMPK $\alpha 2$, FGFR1, PGC-1 $\alpha$, SIRT1, ACC $\mathrm{p}^{(\mathrm{cer} 79)}$, ACC, and PPAR $\alpha$ (Upstate, Lake Placid, NY), FGFR3 (Bioworld Inc, Visalia, CA), antiphosphotyrosine 20 (PY 20), insulin receptor beta (IR $\beta$ ), sterol regulatory element-binding protein (SREBP) 1c, and $\beta$ Klotho antibodies (Santa Cruz Biotech Inc, Santa Cruz, CA), and $\beta$-actin (Affinity BioReagents Inc, Golden, $\mathrm{CO}$ ) using Chemiluminescence Reagent Plus from PerkinElmer Life
Science (Boston, MA), and quantified via a Bio-Rad universal hood II densitometer with Quantity One software (v 4.5; BioRad, Hercules, CA). The highly conserved structural protein $\beta$-actin was used to normalize protein data and specific protein phosphorylation was normalized by its corresponding protein, as stated in the figure captions.

\section{Liver PI 3K activity assay}

Hepatic IRS-1-associated PI 3K activities at baseline (0 minutes) and 10-minutes post-insulin stimulation (2 U/kg body weight via intraperitoneal injection) were assessed as previously described. ${ }^{23}$ Briefly, $500 \mu \mathrm{g}$ of liver lysate protein was immunoprecipitated with $3 \mu \mathrm{g}$ of IRS-1 antibody and protein A agarose. IRS-1 immune complexes were incubated $\left(10\right.$ minutes, $\left.22^{\circ} \mathrm{C}\right)$ in $50 \mu \mathrm{L}$ of $20 \mathrm{mM}$ Tris/ $\mathrm{HCl}(\mathrm{pH} 7.0)$ buffer containing $50 \mu \mathrm{M}\left[\gamma^{32} \mathrm{P}\right]$ adenosine 5 '-triphosphate ( $5 \mu \mathrm{Ci}$; PerkinElmer), $10 \mathrm{mM} \mathrm{MgCl}_{2}, 2 \mathrm{mM}$ $\mathrm{MnCl}_{2}, 100 \mathrm{mM} \mathrm{NaCl}, 2 \mathrm{mM}$ ethylenediaminetetraacetic acid, and $10 \mu \mathrm{g}$ of phosphatidylinositol (PI). After thinlayer chromatography, isotope-labeled phosphatidylinositol 3-phosphate (PI-3P) was visualized by autoradiography and quantitated by densitometer.

\section{Liver FGF2I content assessment}

Liver tissues ( $\sim 25 \mathrm{mg}$ ) were minced with scissors in ten volumes of homogenization buffer $(\mathrm{w} / \mathrm{v})$ in a microcentrifuge tube and homogenized using a Bio-Gen Pro 200 microhomogenizer (PRO Scientific, Oxford, CT). Samples were centrifuged at $15000 \mathrm{~g}$ for 15 minutes. For FGF21 measurement, $50 \mu \mathrm{L}$ of supernatant was used with a Mouse FGF-21 ELISA Kit (R\&D Systems, Minneapolis, MN), according to instructions of the manufacturer. The FGF21 standard ranges were from 82 to $6667 \mathrm{pg} / \mathrm{mL}$. Intra- and interassay coefficients of variation (CVs) of FGF21 were $4.5 \%$ and $6.1 \%$, respectively. The result of FGF21 quality control was $278 \mathrm{pg} / \mathrm{mL}$ (range 191-319 pg/mL).

\section{RNA isolation, reverse transcription, and quantitative polymerase chain reaction (PCR)}

RNA was isolated from liver tissues using TRIzol $^{\circledR}$ reagent (Invitrogen, Carlsbad, CA) and purified using an RNeasy Mini Kit (Qiagen, Valencia, CA). Isolated RNA was reverse transcribed into cDNA by following the protocol of the SuperScript III First-Strand Synthesis System (Invitrogen). The primer sequences of candidate genes were designed using Primer Express ${ }^{\circledR}$ Software (v 3.0; Applied Biosystems, Foster, CA) and are shown in Table 1. All primers were ordered 
Table I Sequence of listing primers

\begin{tabular}{llll}
\hline Accession number & Gene & Primer sequence & Reverse \\
\cline { 3 - 3 } & & Forward & GGAAGAGTCAGGACGCATAGCT \\
\hline NM_0200I3 & FGF2I & GACCCCCTGAGCATGGTAGAG & GTTGTCTGGCCCGATCTTACTC \\
NM_001079908 & FGFRI & CGATCCGCAGCCTCACAT & CCGTTCACTTCCACGTGCTT \\
NM_008010 & FGFR3 & GCAAGGTGTACAGCGATGCA & GACTAAATTTTGCATGTGTGCATCT \\
NM_0III44 & PPAR $\alpha$ & CAAGAGGCTGTGTGACCTAGTGA & GCTCGCAGCAGAACAAACG \\
NM_03II80 & $\beta$ Klotho & TCCAACAGGGCACTGCAAA & TCCATCTGTCAGTGCATCAAATG \\
NM_008904 & PGCI $\alpha$ & GGACAGTCTCCCCGTGGAT & TGCCGGAGCCGTTGTC \\
NM_007393 & $\beta$-actin & ACCAGTTCGCCATGGATGAC & \\
\hline
\end{tabular}

from Integrated DNA Technologies, Inc (Coralville, IA). The quantitative PCR reaction was conducted in 384-well PCR reaction plates on an ABI Prism Sequence Detector 7900 (Applied Biosystems) with Bio-Rad iTaqTM SYBR Green Supermix ROX Kits (Hercules, CA). PCR amplification was performed in duplicate and was normalized to $\beta$-actin.

\section{Statistical analysis}

Results were expressed as mean \pm standard error of the mean. Differences between two groups were tested with Student's unpaired $t$ test. Differences among the four groups were tested using one-way analysis of variance and least-significant difference or Tamhane's T2 tests. ${ }^{24}$

A $P$ value $\leq 0.05$ was considered statistically significant.

\section{Results}

\section{Effects of dietary fibers on glucose and lipid metabolism, hormones, and body weight in mice fed a HFD}

Data on body weight, blood glucose, insulin, GLP-1 and leptin from this animal cohort have been reported previously, and are outlined in Table 1 for demonstration purposes. ${ }^{20}$ In brief, after the 12-week intervention, it was observed that SCF- and PSY-supplemented mice had significantly reduced fasting plasma glucose and insulin and significantly enhanced insulin sensitivity, as measured by HOMA-IR, in comparison with mice fed only a HFD $(P<0.05$ and $P<0.01$, respectively; Table 2). Moreover, SCF significantly reduced fasting plasma triglyceride levels and body weight but only modestly decreased plasma cholesterol. In contrast, CEL-supplemented mice had significantly reduced insulin sensitivity in comparison with mice fed only a HFD $(P<0.05)$. Mice in PSY and SCF supplement groups had reduced plasma leptin and increased GLP-1 levels compared with those in the HFD group, but there was no difference between the CEL and HFD groups. Interestingly, intervention with all of the dietary fibers did not appear to significantly alter caloric intake (Table 2).

\section{Effects of dietary fibers on hepatic lipid content, FGF2I signaling and gene expression of FGF2I signaling in mice}

Mice supplemented with PSY had moderately decreased liver triglyceride content and mice supplemented with SCF had

Table 2 Clinical parameters in mice with dietary fiber supplementation

\begin{tabular}{|c|c|c|c|c|}
\hline Group ( $n=9 /$ group) & HFD & CEL & PSY & SCF \\
\hline Caloric intake $(\mathrm{kcal} / \mathrm{kg} / \text { day })^{\prime}$ & $497 \pm 11$ & $494 \pm 18$ & $516 \pm 29$ & $498 \pm 30$ \\
\hline Body weight $(g)^{\prime}$ & $36.1 \pm 1.06$ & $39.6 \pm 1.17^{* \ldots \#}$ & $36.8 \pm 1.67$ & $31.8 \pm 1.14 *$ \\
\hline Fasting glucose $(\mathrm{mg} / \mathrm{dL})^{\prime}$ & $192 \pm 14$ & $182 \pm 10$ & $152 \pm 7^{*}$ & $149 \pm 1 \mid * *$ \\
\hline Fasting insulin $(\mathrm{ng} / \mathrm{mL})^{\prime}$ & $3.94 \pm 0.52$ & $5.24 \pm 0.78^{\#}$ & $3.02 \pm 0.34^{*}$ & $2.36 \pm 0.22 * *$ \\
\hline HOMA-IR & $0.34 \pm 0.003$ & $0.43 \pm 0.003^{*}$ & $0.2 \mathrm{I} \pm 0.00 \mathrm{I} * *$ & $0.16 \pm 0.002^{* *}$ \\
\hline Plasma cholesterol (mg/dL) & $230 \pm 9$ & $234 \pm 9$ & $214 \pm 10$ & $210 \pm 5$ \\
\hline Plasma triglyceride $(\mathrm{mg} / \mathrm{dL})$ & $97 \pm 7$ & $107 \pm 7$ & $95 \pm 7$ & $80 \pm 5^{*}$ \\
\hline Plasma GLP-I (pg/mL)' & $7.04 \pm 1.08$ & $6.84 \pm 0.44$ & $14.1 \pm 1.26 * * *$ & $|4.2| \pm 0.94^{* * *}$ \\
\hline Plasma leptin $(\mathrm{pg} / \mathrm{mL})^{\prime}$ & $3871 \pm 279$ & $5054 \pm 370^{\ldots}$ & $1020 \pm 196 * * *$ & $1097 \pm 257^{* * * *}$ \\
\hline
\end{tabular}

Notes: Plasma samples were collected at study week II after 4 hours of fasting. Mean \pm SEM ( $n=9 /$ group), *P $<0.05 ; * * P<0.0$ I; ***P $<0.00$ I, dietary fiber group vs HFD group; ${ }^{\#}$ < 0.01 ; \#P $<0.00$ I, SCF or PSY vs CEL group. 'Data from Wang ZQ, Zuberi AR, Zhang XH, et al. Effects of dietary fibers on weight gain, carbohydrate metabolism, and gastric ghrelin gene expression in mice fed a high-fat diet. Metabolism. 2007;56(I2): I635-1642. ${ }^{20}$

Abbreviations: CEL, cellulose; GLP-I, glucagon-like peptide I; HFD, high-fat diet; HOMA-IR, homeostasis model assessment - insulin resistance; PSY, psyllium; SCF, sugar cane fiber. 
significantly reduced liver triglyceride content in comparison with mice in the HFD and CEL groups and there was no significant difference between the HFD and CEL groups. SCF also significantly reduced liver cholesterol content in comparison with $\mathrm{CEL}(P<0.05$, Figure $1 \mathrm{~A}$ and $\mathrm{B})$. However, the lipid content in the liver did not significantly differ between PSY and SCF animals when compared with control. It was also observed that all fibers significantly increased cholesterol content in feces. PSY and SCF greatly increased glycerol content in feces, but CEL did not alter feces glycerol levels when compared with the HFD group (Figure S2B and C). FGF21 levels in the hepatic lysates were significantly lower in the SCF mice than in the HFD and CEL mice (Figure 2A). To evaluate the effects of dietary fibers on FGF21 signaling, hepatic FGF21 signaling proteins were also measured by western blotting. The data show that SCF significantly increased $\beta$ Klotho, FGFR1, FGFR3, and PPAR $\alpha$ protein abundance (first three proteins $P<0.01$; PPAR $\alpha P<0.001$ ). CEL and PSY significantly increased PPAR $\alpha$ content when compared with the HFD alone $(P<0.05$, Figure $2 \mathrm{~B})$. All the dietary fibers modestly increased hepatic PGC- $1 \alpha$ content in comparison with the HFD alone, but there were no significant differences between these groups $(P=\mathrm{NS})$. Except for unaltered $F G F 21 \mathrm{mRNA}$, gene expression analysis shows a similar pattern to FGF21 signaling protein content measured by western blotting in the dietary supplemented mice: SCF significantly increased gene expression of $\beta$ Klotho, FGFR1, FGFR3, PPAR $\alpha$, and PGC-1 $\alpha$ in the livers of mice supplemented with this, compared with mice in the HFD group (Figure 3A); PSY only significantly increased $\beta$ Klotho, while CEL significantly increased $\beta$ Klotho, FGFR1, and PPAR $\alpha$ mRNA content. None of the dietary fibers significantly altered hepatic FGF21 gene expression (Figure 3A). In addition, the gene expression of $\beta$ Klotho, FGFR1, and

A Liver triglyceride content in mice

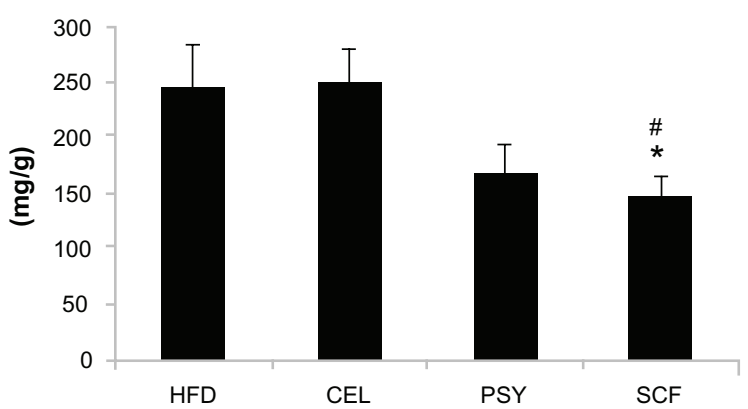

PPAR $\alpha$ in the PSY group was significantly lower than in the $\mathrm{SCF}$ group. There were no significant correlations between FGF21 protein and FGF21 mRNA, between FGF21 mRNA and $P G C-1 \alpha$ mRNA, or between FGF21 mRNA and PPAR $\alpha$ mRNA ( $\mathrm{r}=0.06,0.269$, and 0.07 , respectively, $P=\mathrm{NS}$ ). However, there were significant correlations in the gene expression between hepatic $P G C-1 \alpha$ and $P P A R \alpha$ (Figure 3B) and between PPAR $\alpha$ and FGFR1 (Figure 3C). There was no relationship between hepatic FGF21 and FGFR1 (Figure 3D) and significant negative correlation between $F G F 21$ and $F G F R 3$ in all groups of mice (Figure 3E). There were significant relationships in the gene expression between $P G C-1 \alpha$ and $\beta$ Klotho (Figure 3F) and between PGC-1 $\alpha$ and FGFRI (Figure 3G).

\section{Effects of dietary fibers on hepatic insulin signaling in mice}

Since SCF and PSY significantly reduced glucose and insulin concentrations and increased insulin sensitivity, we further evaluated the effects of these dietary fibers on hepatic insulin signaling in all groups of animals. It was shown that SCF supplementation significantly increased tyrosine phosphorylation of IRS-1, IR, and Akt1 in comparison with an unsupplemented HFD $(P<0.01$ and $P<0.001$, Figure 4A), while PSY significantly increased basal and insulin-stimulated $P Y$ 20 content (Figure 4A). CEL greatly increased basal and insulin-stimulated phosphorylation of Akt1 content. CEL and PSY did not alter phosphorylation of PY 20, IRS-1, or IR. Thus, SCF supplementation significantly increased hepatic phosphorylation of PY 20, IR, and Akt1 and significantly increased insulin-stimulated phosphorylation of IRS-1, but not basal. SCF also greatly increased PI $3 \mathrm{~K}$ activity at basal and insulin-stimulated conditions in mice $(P<0.001$ and $P<0.01$, Figure 4B). CEL modestly increased PI $3 \mathrm{~K}$ activity

B

Liver cholesterol content in mice

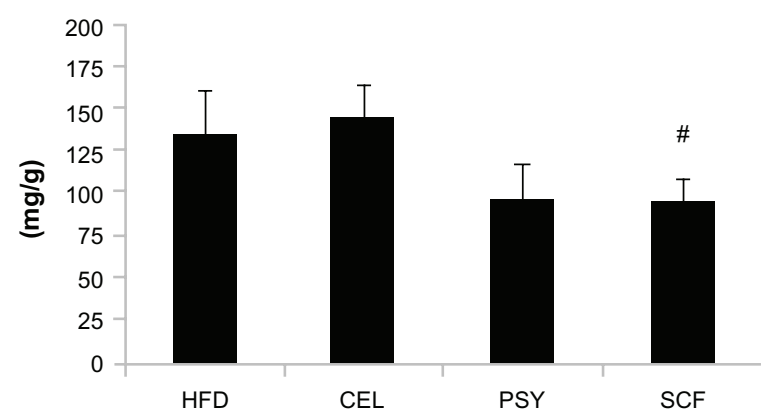

Figure I Effects of dietary fiber on hepatic lipid content in mice fed a HFD. Triglyceride and cholesterol levels in liver were measured after lipid extraction as described in the methods. (A) shows liver triglyceride concentration and (B) shows liver cholesterol levels. The results were normalized by protein concentrations. Notes: Mean \pm standard error of the mean $\left(n=9 /\right.$ group). $* P<0.05$, SCF-supplemented group vs HFD-only group; ${ }^{\# P}<0.05$, SCF vs CEL. Abbreviations: CEL, cellulose; HFD, high-fat diet; PSY, psyllium; SCF, sugar cane fiber. 


\section{A}

\section{Liver FGF21 content in mice}

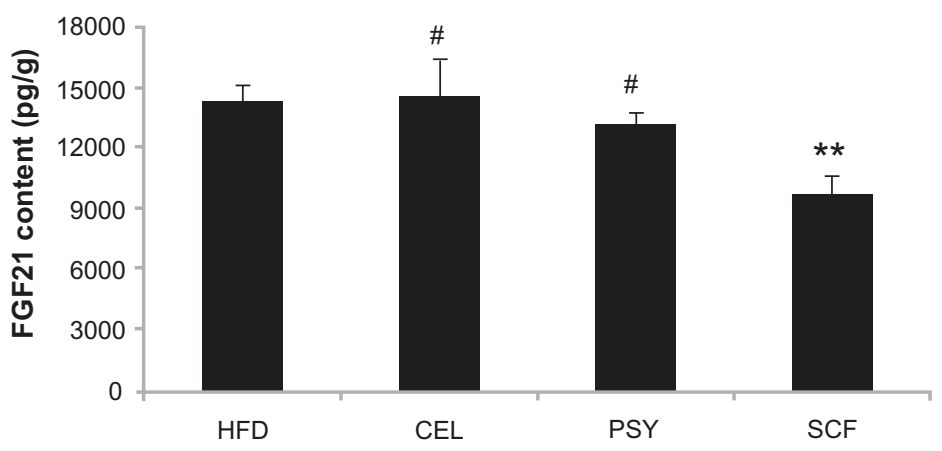

B
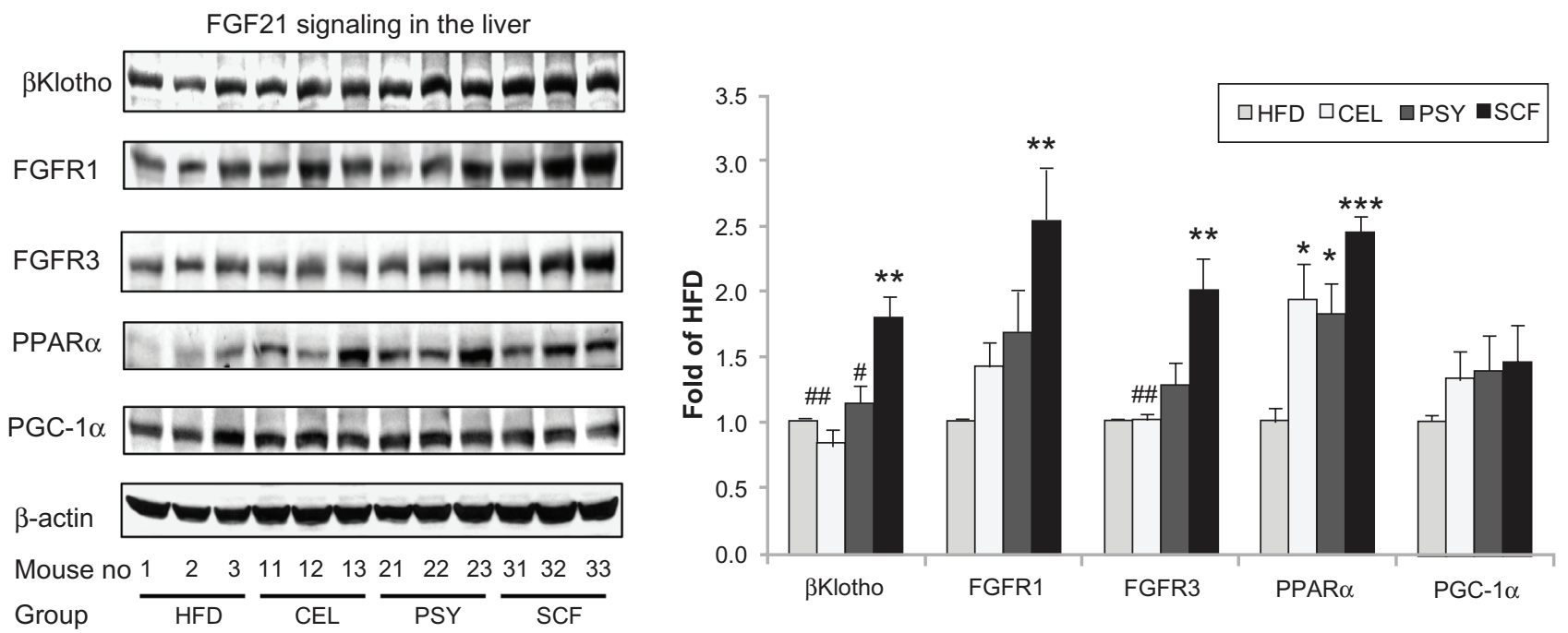

Figure 2 Hepatic fibroblast growth factor (FGF) 2 I signaling in mice treated with dietary fiber. (A) FGF2I content of liver lysates, as measured by Rat/Mouse Fibroblast Growth Factor 2I (FGF2I) ELISA Kit from Millipore (Billerica, MA). Hepatic FGF2I proteins were measured by western blotting. Liver lysates were subjected to sodium dodecyl sulfate polyacrylamide gel electrophoresis, then transferred into nitrocellulose membranes. $\beta$ Klotho, fibroblast growth factor receptor (FGFR) I, FGFR3, peroxisome proliferator-activated receptor alpha (PPAR $\alpha$ ), and peroxisome proliferator-activated receptor $\gamma$ coactivator protein I alpha (PGC-I $\alpha$ ) were determined using their corresponding specific antibodies, shown in (B). Results were normalized with $\beta$-actin.

Notes: Mean \pm standard error of the mean $\left(n=9 /\right.$ group). ${ }^{*} P<0.05 ; * * P<0.01$; $* * * P<0.00$ I, dietary fiber group vs HFD group; ${ }^{*} P<0.05$; ${ }^{*} P<0.0$ I, CEL or PSY vs SCF group.

Abbreviations: CEL, cellulose; HFD, high-fat diet; PSY, psyllium; SCF, sugar cane fiber.

relative to the HFD group. PSY had significantly reduced insulin-stimulated PI $3 \mathrm{~K}$ activity when compared with the SCF group $(P<0.0001$, Figure 4B).

\section{Effects of dietary fiber supplementation on hepatic AMPK signaling in mice}

FGF21 regulates energy homeostasis in adipocytes through the activation of AMPK and SIRT1, resulting in enhanced mitochondrial oxidative function. ${ }^{11}$ AMPK signaling pathway proteins in the liver were measured and data show that supplementation with all three dietary fibers significantly increased phosphorylation of AMPK [AMPK $\mathrm{p}^{\text {(Thr172) }}$. Phosphorylated AMPK abundance was increased about 2.5-fold in the SCF group and 1.5 1.4 fold in the CEL and
PSY groups compared with the HFD group $(P<0.001$ and $P<0.05$, respectively). Only SCF significantly increased AMPK $\alpha 1$ protein abundance $(P<0.05)$, but none of the three fibers were found to have altered AMPK $\alpha 2$ protein content when the supplemented animals were compared with those in the HFD group. Mice fed dietary fibers had significantly higher levels of ACC phosphorylation than the HFD animals. The ratio of ACC $\mathrm{p}$ to ACC increased 2.45-fold $(P<0.05)$ in the CEL, 3.91-fold $(P<0.01)$ in the PSY, and 4.45 -fold $(P<0.001)$ in the SCF supplemented groups in comparison with the HFD group. Although hepatic SIRT1 and SREBP 1c were modestly increased in the SCF mice, there were no significant differences among all the groups (Figure 5). 
A

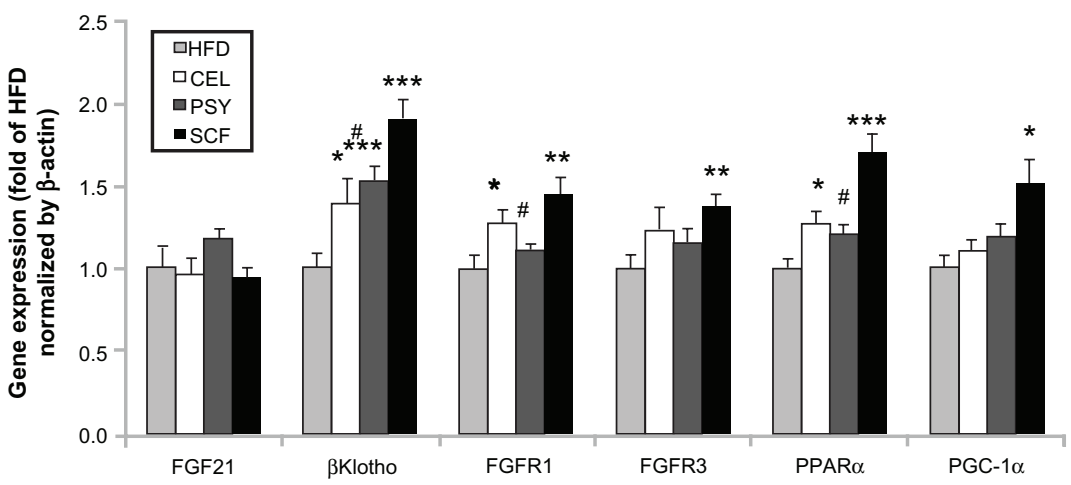

B Correlation between hepatic PGC-1 $\alpha$ and PPAR $\alpha$

C Correlation between hepatic FGFR1 and PPAR $\alpha$
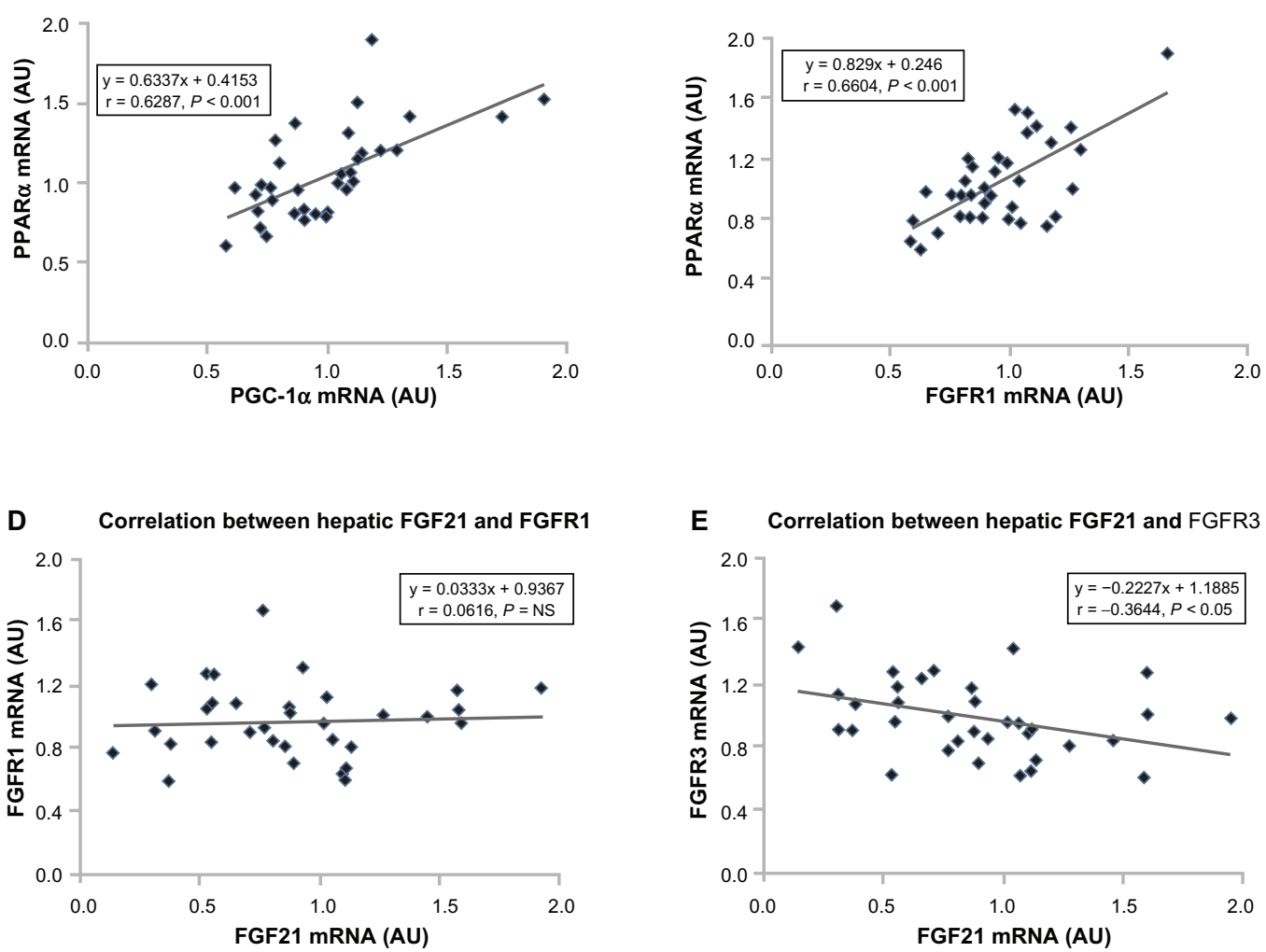

F Correlation between hepatic PGC-1 $\alpha$ and $\beta$ KIotho

G Correlation between hepatic PGC-1 $\alpha$ and FGFR1
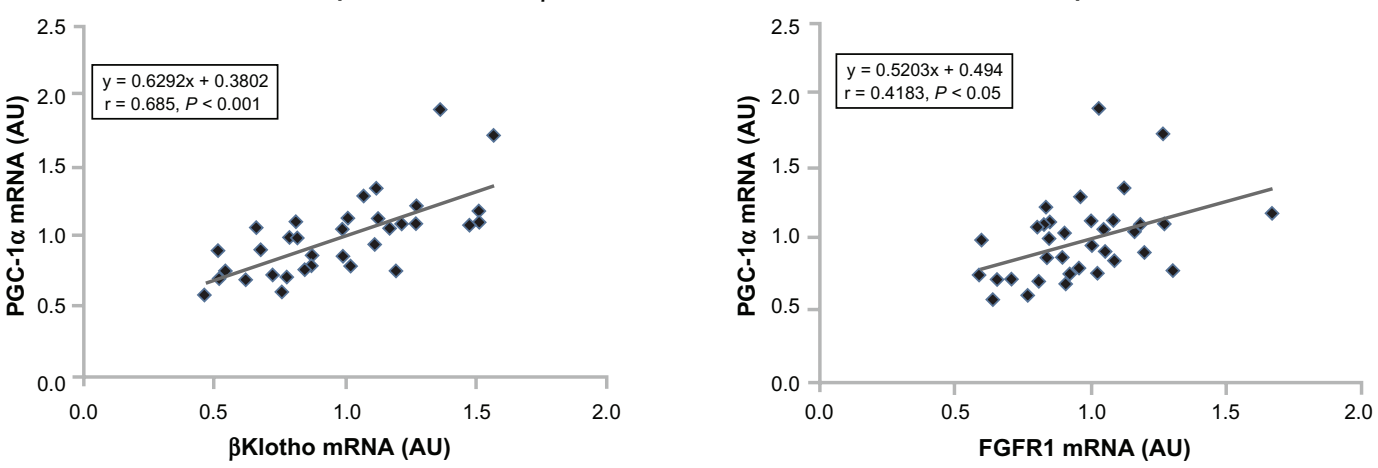

Figure 3 Gene expression of fibroblast growth factor (FGF) 2 I signaling pathway in the liver and correlation between the gene levels. Hepatic FGF2I signaling-related gene expression was analyzed by real-time polymerase chain reaction assay. (A) FGF2I and its related gene expression levels; (B-G) show the correlations among genes. Notes: Mean \pm standard error of the mean $\left(n=9 /\right.$ group). $* P<0.05 ; * * P<0.01 ; * * * P<0.00$, dietary fiber-supplemented group vs HFD-only group; ${ }^{*} P<0.05, C E L$ or PSY vs SCF group.

Abbreviations: AU, arbitrary unit; CEL, cellulose; HFD, high-fat diet; PPAR $\alpha$, peroxisome proliferator-activated receptor alpha; PGC-I $\alpha$, peroxisome proliferator-activated receptor $\gamma$ coactivator protein I alpha; PSY, psyllium; SCF, sugar cane fiber. 
A

Insulin signaling in the liver

PY 20

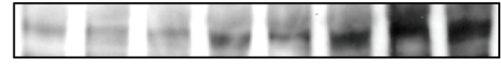

$\beta$-actin

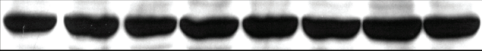

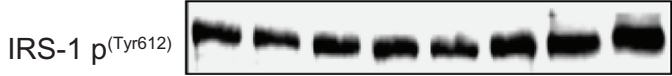

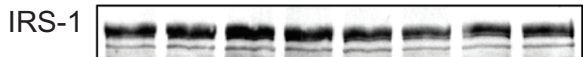

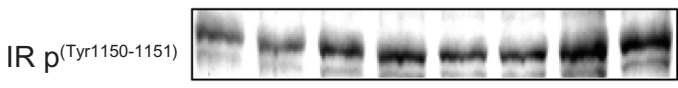

$\operatorname{IR} \beta$
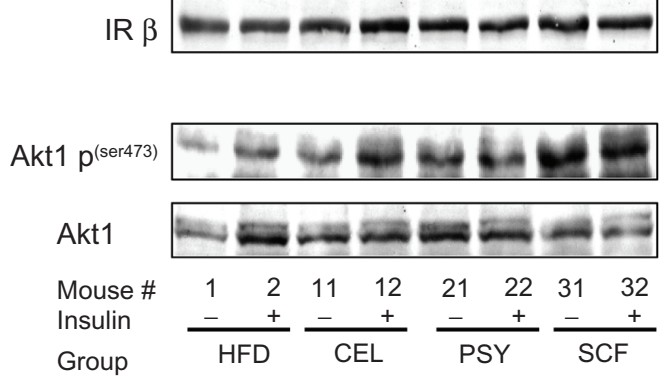

PY 20 content in mice livers

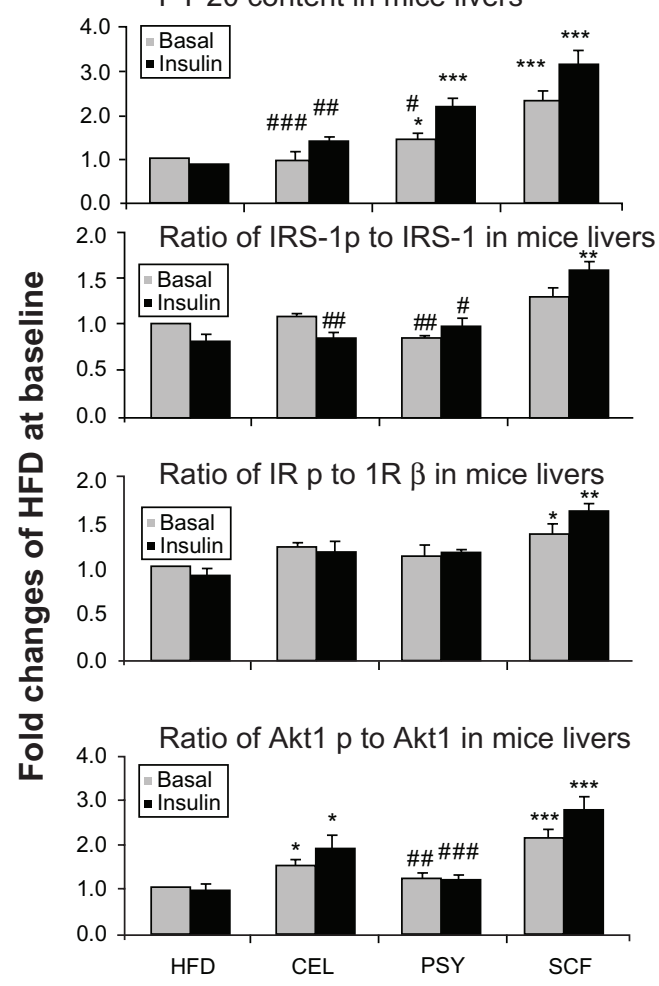

B

IRS-1-associated PI 3K activity in livers
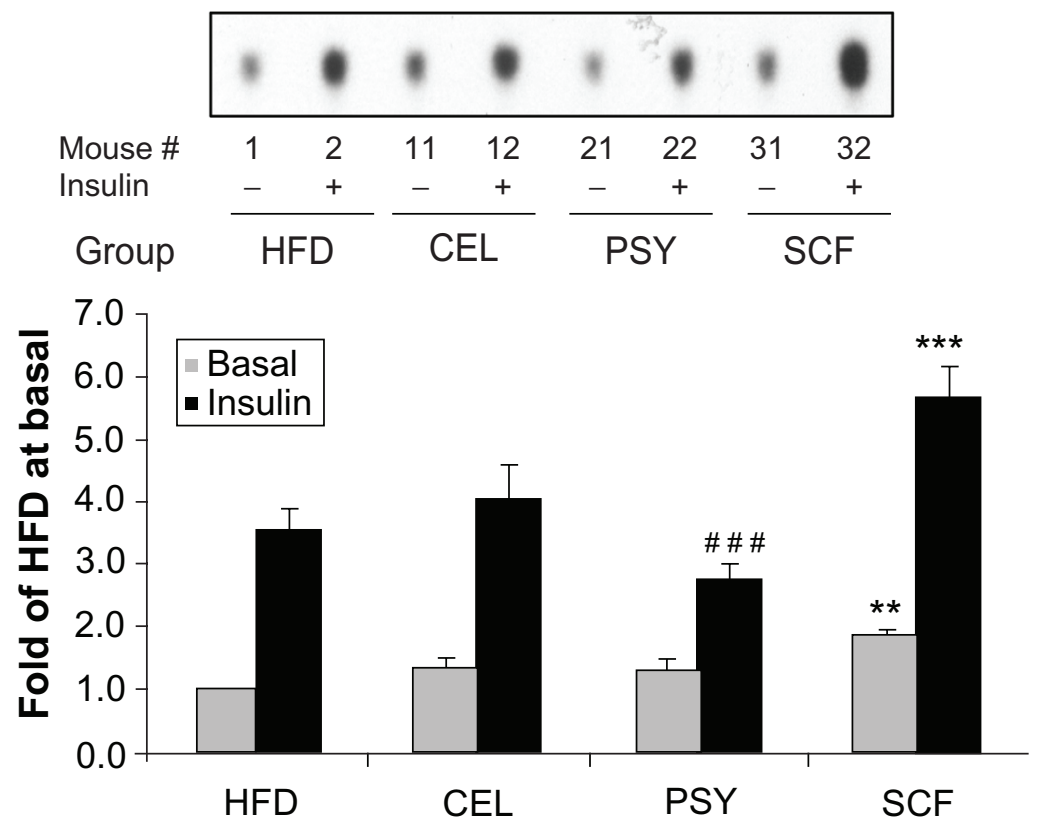

Figure 4 Effects of dietary fibers on insulin signaling protein abundance and phosphatidylinositol 3 kinase (PI 3K) activity in mice livers. Liver lysates were subjected to sodium dodecyl sulfate polyacrylamide gel electrophoresis and insulin signaling pathway proteins were detected with corresponding specific antibodies as shown in the figures. (A) shows that phosphorylation of antiphosphotyrosine 20 (PY 20), insulin receptor substrate (IRS) I, insulin receptor beta (IR $\beta$ ), and Akt I were normalized by their corresponding protein contents and PY 20 was normalized by $\beta$-actin. (B) Hepatic IRS-I-associated PI $3 \mathrm{~K}$ activity in mice. Liver lysates from basal and insulin-stimulated mice were immunoprecipitated with IRS-I antibody and protein A agarose. The immune complexes were incubated with reaction buffer containing $\left[\gamma^{32} \mathrm{P}\right]$ adenosine $5^{\prime}$ triphosphate, $\mathrm{MgCl}_{2}, \mathrm{MnCl}_{2}$, and phosphatidylinositol for 20 minutes. Autoradiograph was performed after thin-layer chromatography.

Notes: Data presented as mean \pm standard error of the mean $(n=9 /$ group $)$. $* P<0.05$; $* * P<0.01$; $* * * P<0.00$ I, dietary fiber-supplemented group vs HFD-only group; ${ }^{\# P}<0.05 ; \# P<0.0$ I; \#\#P $<0.00$ I; CEL or PSY vs SCF group.

Abbreviations: CEL, cellulose; HFD, high-fat diet; PSY, psyllium; SCF, sugar cane fiber. 

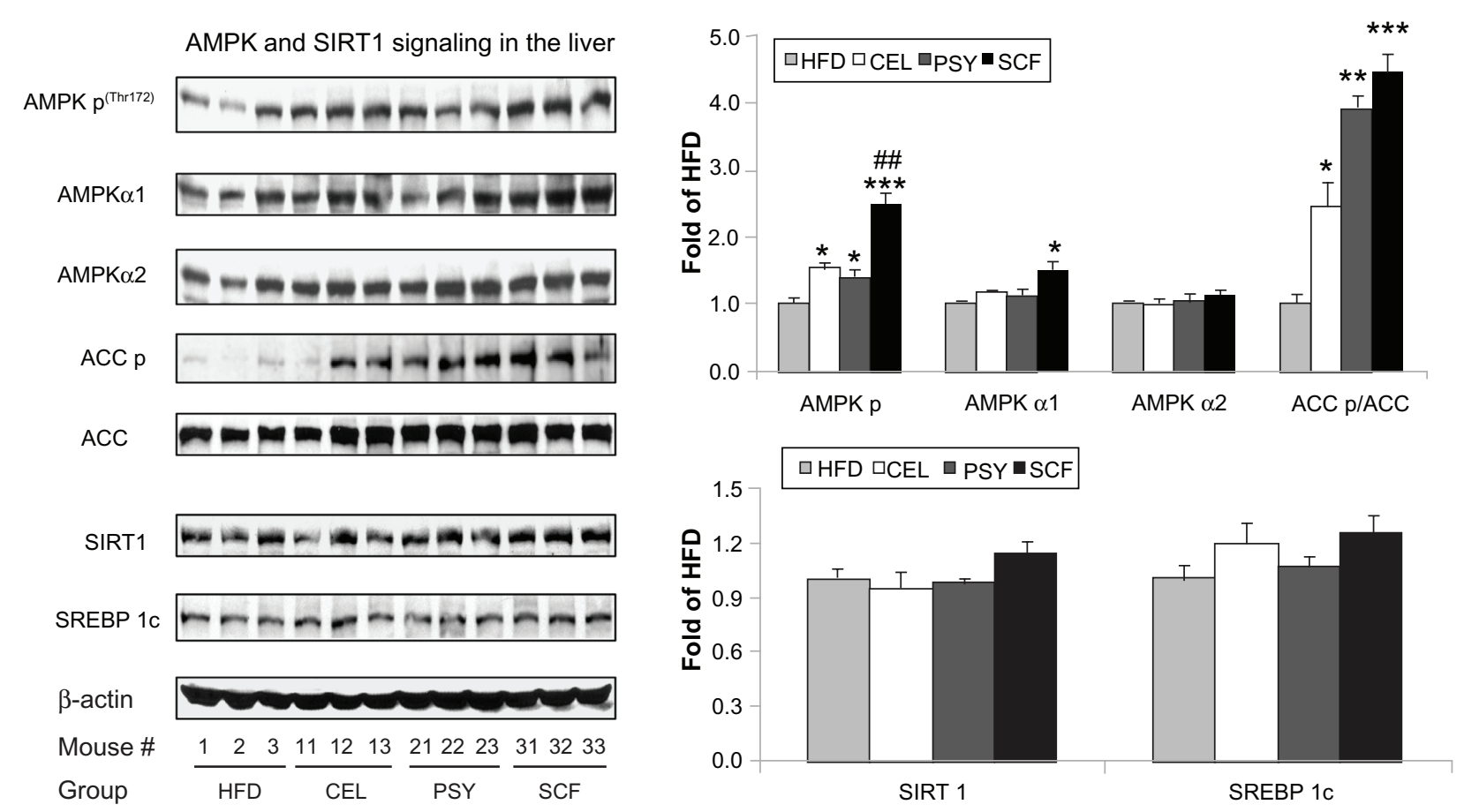

Figure 5 Effects of dietary fibers on liver AMP-activated protein kinase (AMPK) signaling in mice. The protein abundances of AMPK $\alpha$ I, AMPK $\alpha 2$, ACC, SIRTI, sterol regulatory element-binding protein (SREBP) Ic and phosphorylated AMPK $\alpha$, and ACC were measured by immunoblotting.

Notes: Data are shown as mean \pm standard error of the mean $(\mathrm{n}=9 /$ group $)$. $* \mathrm{P}<0.05 ; * * \mathrm{p}<0.0 \mathrm{I}$; $* * * \mathrm{p}<0.00 \mathrm{I}$, dietary fiber-supplemented group vs HFD-only group; \#P $<0.0$ I, CEL or PSY vs SCF group.

Abbreviations: CEL, cellulose; HFD, high-fat diet; PSY, psyllium; SCF, sugar cane fiber.

\section{Discussion}

Dietary fiber has an important role in contributing to metabolic health in humans. Proposed possible mechanisms for metabolic improvements with dietary fiber include reduced glucose and lipid absorption, increased hepatic extraction of insulin, improved insulin sensitivity at the cellular level, increased binding of bile acids, and promotion of satiety. ${ }^{17,25,26}$ These effects may be related to its physical properties, structure, and the fiber compositions, particle sizes, amount and type of fiber, viscosity, and soluble and insoluble content. ${ }^{17,20,25}$ Colonic fermentation of naturally available high-fiber foods can also be mainly attributed to soluble fiber, whereas no difference between soluble and insoluble dietary fiber consumption on the regulation of body weight has been observed. ${ }^{27}$ It was also noticed that the consumption of not only soluble dietary fiber but also insoluble cereal dietary fiber and whole grains is consistently associated with a reduced risk of type 2 diabetes in a large prospective cohort study. ${ }^{28}$ Indeed, our prior study revealed that the effects of SCF ( $85 \%$ insoluble fiber) on reducing glucose and lipid levels was greater than PSY (75\% soluble fiber). ${ }^{20}$ These effects were felt to be mediated in part by SCF's nano-sized particles and by its bioactive components.
Dietary fiber consumption was demonstrated to contribute to a number of metabolic effects in addition to changes in body weight. These favorable effects included improved insulin sensitivity, modulation of the secretion of certain gut hormones, and alteration of various metabolic and inflammatory markers associated with metabolic syndrome. . $^{18,29}$

\section{Comparison of the effects of dietary fibers on hepatic insulin signaling}

Obesity is a condition that impairs multiple cellular signaling pathways, resulting in resistance to FGF21, insulin, and leptin. ${ }^{15,16,20}$ In this study, we observed that SCF and PSY supplementation significantly enhanced hepatic insulin signaling (Figure 4) in comparison with a HFD alone. SCF, which significantly increased both basal and insulin-stimulated tyrosine phosphorylation of IRS-1, IR $\beta$, and Akt1, appears to be the most effective of the three dietary fibers studied. In contrast, CEL supplementation in this study affected neither plasma glucose nor hepatic insulin signaling. In insulin-resistant states, elevated free fatty acid flux into the intestine, downregulation of intestinal insulin signaling, and upregulation of microsomal triglyceride transfer protein all appear to stimulate intestinal 
lipoprotein production. Gut peptides - that is, GLP-1 and GLP-2 - may be important regulators of intestinal lipid absorption and lipoprotein production. ${ }^{30}$ Therefore, SCF and PSY, by significantly elevating plasma GLP-1 levels, could be said to mediate the favorable lipid effects via modulation of these incretins. ${ }^{20}$ GLP-1 also mediates its effect on gastrointestinal motility, appetite, food intake, and glucagon secretion directly in an amylin-independent fashion. ${ }^{31}$ Moreover, long-term treatment with GLP-1 or its analog can improve insulin sensitivity, as it was observed that GLP-1 and exendin-4 (a peptide analog of GLP-1) increased insulin-mediated glucose uptake in intact and tumor necrosis factor-alpha-treated 3T3-L1 adipocytes by increasing phosphorylated IR $\beta$, IRS-1, Akt, and glycogen synthase kinase $3 .{ }^{32} \mathrm{~A}$ single administration of a recombinant adenovirus expressing GLP-1 was shown to result in the long-term remission of diabetes in ob/ob mice by improving insulin sensitivity via restoration of insulin signaling and reduction of hepatic gluconeogenesis. ${ }^{33}$

\section{SCF significantly enhanced hepatic FGF2I signaling}

Other studies have shown that transgenic mice with over expression of FGF21 were resistant to DIO and metabolic disturbances, while FGF21 administration enhanced insulin sensitivity in insulin resistant animals. ${ }^{11,12}$ However, it was recently reported that increased levels of FGF21 can be an independent risk factor related to metabolic syndrome and can also represent an independent predictor of liver steatosis. ${ }^{34,35}$ The paradoxical increase of serum FGF21 levels in obese individuals may be explained by a compensatory response or resistance to FGF21. ${ }^{36}$ In the present study, SCF supplementation significantly reduced hepatic FGF21 abundance and increased $\beta$ Klotho, FGFR1, FGFR3, and PPAR $\alpha$ contents in comparison with an unsupplemented HFD, indicating FGF21 negative feedback regulates its receptors, while PSY and CEL modestly altered liver FGF21 signaling. Although plasma FGF21 concentrations were not available in this study, liver FGF21 content measured using enzyme-linked immunosorbent assay may mirror plasma FGF21 levels, since the liver is the major source of circulating FGF21. Conversely, no significant relationship between hepatic FGF21 protein abundance and FGF21 mRNA levels was observed. The effects of dietary fiber on post-translational modification, such as alteration in the rates of protein synthesis and degradation, are not precisely known.

Another possible mechanism is that SCF may have significantly reduced hepatic FGF21 content by enhancing
FGF21 signaling. Consistent with findings that FGF21 reverses hepatic steatosis, increases energy expenditure, and improves insulin sensitivity in DIO mice, ${ }^{37}$ our data reveal that SCF supplementation significantly enhanced both liver FGF21 and insulin signaling in mice in comparison with a HFD alone. Based on the evidence that hyperinsulinemia induces skeletal muscle production of FGF $21^{16}$ and a PI $3 \mathrm{~K} /$ Akt1 signaling pathway-dependent mechanism also regulates FGF2 $1,{ }^{38}$ the effects of SCF on enhancing insulin signaling and attenuating insulin resistance may greatly help to reduce liver FGF21 content. Alternatively, FGF21 treatment has been found to induce mRNA and protein expression of PGC- $1 \alpha$, suggesting that PGC- $1 \alpha$ may play a role in regulating FGF21 action. ${ }^{39}$ However, our finding that all dietary fibers did not significantly alter PGC- $1 \alpha$ indicates that the effect of SCF on FGF2 1 is not dependent on PGC-1 $\alpha$ because SCF significantly reduced rather than increased hepatic FGF21 content.

All animals supplemented with dietary fiber demonstrated significantly increased hepatic phosphorylation of AMPK independent of SIRT1 and SREBP 1c. It is well documented that activation of AMPK can greatly increase fatty acid oxidation and inhibit lipid synthesis and glucose production by modulating the transcription of genes involved in lipogenesis and mitochondrial biogenesis. ${ }^{40,41}$ HFD supplementation with dietary fiber, especially SCF, dramatically increased hepatic phosphorylation of AMPK and ACC in comparison with a HFD alone $(P<0.05$ in CEL and PSY and $P<0.001$ in SCF, respectively). However, none of these fibers were shown to affect SIRT1 and SREBP 1c content.

Our data suggest that the effects of dietary fiber on activation of hepatic AMPK signaling may not be associated with the SIRT1 and SREBP 1c pathways. Enhanced AMPK signaling in the SCF-treated mice could also account for the reduction of plasma glucose and lipid levels and the attenuation of hepatic lipid accumulation. Short-chain fatty acids produced during the colonic fermentation of fiber beneficially influence circulating concentrations of free fatty acids and gut hormones involved in the regulation of blood glucose and body mass. ${ }^{42}$ Butyrate - a major end product of dietary starch and fiber produced naturally during digestion by anaerobic bacteria in the cecum and colon - may be a contributing mechanism for increased endogenous secretions of total GLP-1 and peptide YY (PYY) in rodents. ${ }^{43}$ A more recent study revealed that different fiber sources can induce different physiological responses in overweight cats, including the reduction of energy digestibility, greater inclination to favor glucose metabolism (with SCF), or gut health improvement (with beet pulp), according to their different solubilities 
and fermentation rates. ${ }^{44}$ On the other hand, to serve as a sorbent material in the gut, smaller particles of dietary fiber may be more active than the coarse, because more smallsized particles than large-sized particles greatly increases the surface area in the same weight of fiber. Therefore, both fiber source and particle size may play an important role in fermentability and energy intake. Indeed, in this study, dietary fiber not only significantly increased the amount of feces through its bulk effect (Figure S2A) but also reduced lipid absorption. We observed that the glycerol content of feces was significantly higher in the PSY and SCF groups and the cholesterol content of feces was significantly higher in all three fiber groups than in the HFD group (Figure S2A-C).

Unlike CEL and PSY, the effects of SCF on enhanced cellular signaling may also be attributed to its bioactive components such as policosanol, a natural compound derived from sugar cane wax, and other unidentified molecules. Policosanol has been demonstrated to activate AMPK and 3-hydroxy-3-methyl-glutaryl coenzyme A reductase in hepatoma cells and in mouse liver after intragastric administration. ${ }^{45}$ Moreover, nano-sized SCF was more effective than non-nano-sized CEL and PSY because the smaller particles are more activated than the coarser particles. Although we did not measure butyrate levels, our data show that SCF significantly increased hepatic AMPK phosphorylation and plasma GLP-1 concentrations, supporting the notion that butyrate may induce AMPK activation through expression of GLP-1. ${ }^{46}$

It has been found that the ability of GLP-1 to reduce food intake has a central mechanism, as GLP-1 centrally administered in the lateral ventricles of rats significantly reduced food intake, strongly suggesting that GLP-1 acts through a direct central nervous system-mediated mechanism to control food intake. ${ }^{47}$ Therefore, the reason why SCF did not affect food intake in our study may be that the endogenously elevated GLP-1 from SCF ingestion was insufficient to affect satiety when compared with central injection of exogenous GLP-1. Taken together, SCF enhanced multiple cellular signaling and promoted cross-talking in signaling pathways that may be mediated by gastrointestinal factors such as GLP-1, ghrelin, and butyrate.

\section{Conclusion}

SCF appears to have enhanced metabolic effects over CEL and PSY in improving glucose and lipid metabolism in mice fed a HFD. SCF significantly enhanced hepatic FGF21, insulin and AMPK signaling in this study. This has extended our insight into the possible mechanisms that may underlie the beneficial effects of dietary fiber, suggesting that gastrointestinal factors such as ghrelin, GLP-1, and butyrate may play a crucial role in enhancing FGF21, insulin, and AMPK signaling, consequently attenuating NAFLD and insulin resistance.

\section{Authors' contributions}

ZQW designed the study, wrote, and edited the manuscript. $\mathrm{XHZ}$ and YMY researched data. KL invented the technology of SCF. ZEF, AB, and WTC reviewed and edited the manuscript. All authors read and approved the final version of the manuscript. ZQW had primary responsibility for the final content.

\section{Acknowledgments}

This project was supported in part by P50AT002776-01 (WTC) from the National Center for Complementary and Alternative Medicine (NCCAM) and the Office of Dietary Supplements (ODS), which funds the Botanical Research Center of Pennington Biomedical Research Center and The Biotech Center of Rutgers University. In addition, support was obtained from American Sugarcane League as an award to ZQW. The authors would like to thank Susan Newman for her assistance with the real-time PCR assay at Genomics Core Facility, which is supported in part by COBRE (NIH P20-RR021945) and NORC (NIH 1P30-DK072476) center grants from the National Institutes of Health. We acknowledge the assistance of Russell Tipton (Pennington Biomedical Research Center) in preparing the manuscript.

\section{Disclosure}

Other than the funding outlined in the Acknowledgments, the authors declare no conflicts of interest in this work.

\section{References}

1. Zivkovic AM, German JB, Sanyal AJ. Comparative review of diets for the metabolic syndrome: implications for nonalcoholic fatty liver disease. Am J Clin Nutr. 2007;86(2):285-300.

2. Chan JM, Rimm EB, Colditz GA, Stampfer MJ, Willett WC. Obesity, fat distribution, and weight gain as risk factors for clinical diabetes in men. Diabetes Care. 1994;17(9):961-969.

3. Silverman JF, O'Brien KF, Long S, et al. Liver pathology in morbidly obese patients with and without diabetes. Am J Gastroenterol. 1990;85(10):1349-1355.

4. Fritsche L, Weigert C, Häring HU, Lehmann R. How insulin receptor substrate proteins regulate the metabolic capacity of the liver-implications for health and disease. Curr Med Chem. 2008;15(13):1316-1329.

5. Lizcano JM, Alessi DR. The insulin signalling pathway. Curr Biol. 2002;12(7):R236-R238.

6. Kharitonenkov A. FGFs and metabolism. Curr Opin Pharmacol. 2009;9(6):805-810.

7. Nishimura T, Nakatake Y, Konishi M, Itoh N. Identification of a novel FGF, FGF-21, preferentially expressed in the liver. Biochim Biophys Acta. 2000;1492(1):203-206. 
8. Mai K, Bobbert T, Groth C, et al. Physiological modulation of circulating FGF21: relevance of free fatty acids and insulin. Am J Physiol Endocrinol Metab. 2010;299(1):E126-E130.

9. Potthoff MJ, Inagaki T, Satapati S, et al. FGF21 induces PGC-1alpha and regulates carbohydrate and fatty acid metabolism during the adaptive starvation response. Proc Natl Acad Sci U S A. 2009;106(26): 10853-10858

10. Inagaki T, Dutchak P, Zhao G, et al. Endocrine regulation of the fasting response by PPARalpha-mediated induction of fibroblast growth factor 21. Cell Metab. 2007;5(6):415-425.

11. Kliewer SA, Mangelsdorf DJ. Fibroblast growth factor 21: from pharmacology to physiology. Am J Clin Nutr. 2010;91(1): 254S-257S

12. Xu J, Stanislaus S, Chinookoswong N, et al. Acute glucose-lowering and insulin-sensitizing action of FGF21 in insulin resistant mouse models - Association with liver and adipose tissue effects. Am J Physiol Endocrinol Metab. 2009;297:E1105-E1114.

13. Wente W, Efanov AM, Brenner M, et al. Fibroblast growth factor-21 improves pancreatic beta-cell function and survival by activation of extracellular signal-regulated kinase $1 / 2$ and Akt signaling pathways. Diabetes. 2006;55(9):2470-2478.

14. Chau MD, Gao J, Yang Q, Wu Z, Gromada J. Fibroblast growth factor 21 regulates energy metabolism by activating the AMPK-SIRT1-PGC-1alpha pathway. Proc Natl Acad Sci U S A. 2010;107(28):12553-12558.

15. Cuevas-Ramos D, Almeda-Valdes P, Aguilar-Salinas CA, CuevasRamos G, Cuevas-Sosa AA, Gomez-Perez FJ. The role of fibroblast growth factor 21 (FGF21) on energy balance, glucose and lipid metabolism. Curr Diabetes Rev. 2009;5(4):216-220.

16. Hojman P, Pedersen M, Nielsen AR, et al. Fibroblast growth factor-21 is induced in human skeletal muscles by hyperinsulinemia. Diabetes. 2009;58(12):2797-2801.

17. Lyon MR, Reichert RG. The effect of a novel viscous polysaccharide along with lifestyle changes on short-term weight loss and associated risk factors in overweight and obese adults: an observational retrospective clinical program analysis. Altern Med Rev. 2010;15(1):68-75.

18. Wolfram T, Ismail-Beigi F. Efficacy of high-fiber diets in the management of type 2 diabetes mellitus. Endocr Pract. 2011;17(1):132-142.

19. Zhang Z, Lanza E, Kris-Etherton PM, et al. A high legume low glycemic index diet improves serum lipid profiles in men. Lipids. 2010;45(9): 765-775.

20. Wang ZQ, Zuberi AR, Zhang XH, et al. Effects of dietary fibers on weight gain, carbohydrate metabolism, and gastric ghrelin gene expression in mice fed a high-fat diet. Metabolism. 2007;56(12):1635-1642.

21. Folch J, Lees M, Sloane Stanley GH. A simple method for the isolation and purification of total lipides from animal tissues. J Biol Chem. 1957;226(1):497-509.

22. Matthews DR, Hosker JP, Rudenski AS, Naylor BA, Treacher DF, Turner RC. Homeostasis model assessment: insulin resistance and betacell function from fasting plasma glucose and insulin concentrations in man. Diabetologia. 1985;28(7):412-419.

23. Wang ZQ, Zhang XH, Russell JC, Hulver M, Cefalu WT. Chromium picolinate enhances skeletal muscle cellular insulin signaling in vivo in obese, insulin-resistant JCR:LA-cp rats. J Nutr. 2006;136(2): $415-420$.

24. Umpierrez GE, Jones S, Smiley D, et al. Insulin analogs versus human insulin in the treatment of patients with diabetic ketoacidosis: a randomized controlled trial. Diabetes Care. 2009;32(7): 1164-1169.

25. Schulze MB, Schulz M, Heidemann C, Schienkiewitz A, Hoffmann K, Boeing $\mathrm{H}$. Fiber and magnesium intake and incidence of type 2 diabetes: a prospective study and meta-analysis. Arch Intern Med. 2007;167(9):956-965.

26. Tuomilehto J, Lindström J, Eriksson JG, et al. Prevention of type 2 diabetes mellitus by changes in lifestyle among subjects with impaired glucose tolerance. $N$ Engl J Med. 2001;344(18):1343-1350.
27. Schroeder N, Gallaher DD, Arndt EA, Marquart L. Influence of whole grain barley, whole grain wheat, and refined rice-based foods on shortterm satiety and energy intake. Appetite. 2009;53(3):363-369.

28. de Munter JS, Hu FB, Spiegelman D, Franz M, van Dam RM. Whole grain, bran, and germ intake and risk of type 2 diabetes: a prospective cohort study and systematic review. PLoS Med. 2007;4(8):e261.

29. Weickert MO, Pfeiffer AF. Metabolic effects of dietary fiber consumption and prevention of diabetes. J Nutr. 2008;138(3):439-442.

30. Adeli K, Lewis GF. Intestinal lipoprotein overproduction in insulinresistant states. Curr Opin Lipidol. 2008;19(3):221-228.

31. Asmar M. New physiological effects of the incretin hormones GLP-1 and GIP. Dan Med Bull. 2011;58(2):B4248.

32. Gao H, Wang X, Zhang Z, et al. GLP-1 amplifies insulin signaling by up-regulation of IRbeta, IRS-1 and Glut4 in 3T3-L1 adipocytes. Endocrine. 2007;32(1):90-95.

33. Lee YS, Shin S, Shigihara T, et al. Glucagon-like peptide-1 gene therapy in obese diabetic mice results in long-term cure of diabetes by improving insulin sensitivity and reducing hepatic gluconeogenesis. Diabetes. 2007;56(6):1671-1679.

34. Fisher FM, Chui PC, Antonellis PJ, et al. Obesity is a fibroblast growth factor 21 (FGF21)-resistant state. Diabetes. 2010;59(11): 2781-2789.

35. Yilmaz Y, Eren F, Yonal O, et al. Increased serum FGF21 levels in patients with nonalcoholic fatty liver disease. Eur J Clin Invest. 2010;40(10):887-892.

36. Zhang X, Yeung DC, Karpisek M, et al. Serum FGF21 levels are increased in obesity and are independently associated with the metabolic syndrome in humans. Diabetes. 2008;57(5):1246-1253.

37. Xu J, Lloyd DJ, Hale C, et al. Fibroblast growth factor 21 reverses hepatic steatosis, increases energy expenditure, and improves insulin sensitivity in diet-induced obese mice. Diabetes. 2009;58(1):250-259.

38. Izumiya Y, Bina HA, Ouchi N, Akasaki Y, Kharitonenkov A, Walsh K. FGF21 is an Akt-regulated myokine. FEBS Lett. 2008;582(27):3805-3810

39. Fisher FM, Estall JL, Adams AC, et al. Integrated regulation of hepatic metabolism by fibroblast growth factor 21 (FGF21) in vivo. Endocrinology. 2011;152(8):2996-3004.

40. Viollet B, Guigas B, Leclerc J, et al. AMP-activated protein kinase in the regulation of hepatic energy metabolism: from physiology to therapeutic perspectives. Acta Physiol (Oxf). 2009;196(1):81-98.

41. Winder WW, Hardie DG. AMP-activated protein kinase, a metabolic master switch: possible roles in type 2 diabetes. Am J Physiol. 1999;277(1 Pt 1):E1-E10.

42. Tarini J, Wolever TM. The fermentable fibre inulin increases postprandial serum short-chain fatty acids and reduces free-fatty acids and ghrelin in healthy subjects. Appl Physiol Nutr Metab. 2010;35(1): 9-16.

43. Zhou J, Martin RJ, Tulley RT, et al. Dietary resistant starch upregulates total GLP-1 and PYY in a sustained day-long manner through fermentation in rodents. Am J Physiol Endocrinol Metab. 2008;295(5):E1160-E1166.

44. Fischer MM, Kessler AM, de Sá LR, et al. Fiber fermentability effects on energy and macronutrient digestibility, fecal parameters, postprandial metabolite responses, and colon histology of overweight cats. J Anim Sci. 2012. Epub Jan 13.

45. Banerjee S, Ghoshal S, Porter TD. Activation of AMP-kinase by policosanol requires peroxisomal metabolism. Lipids. 2011;46(4): 311-321.

46. Peng L, Li ZR, Green RS, Holzman IR, Lin J. Butyrate enhances the intestinal barrier by facilitating tight junction assembly via activation of AMP-activated protein kinase in Caco-2 cell monolayers. J Nutr. 2009;139(9):1619-1625.

47. Asarian L, Corp ES, Hrupka B, Geary N. Intracerebroventricular glucagon-like peptide-1 (7-36) amide inhibits sham feeding in rats without eliciting satiety. Physiol Behav. 1998;64(3):367-372. 


\section{Supplementary figures}
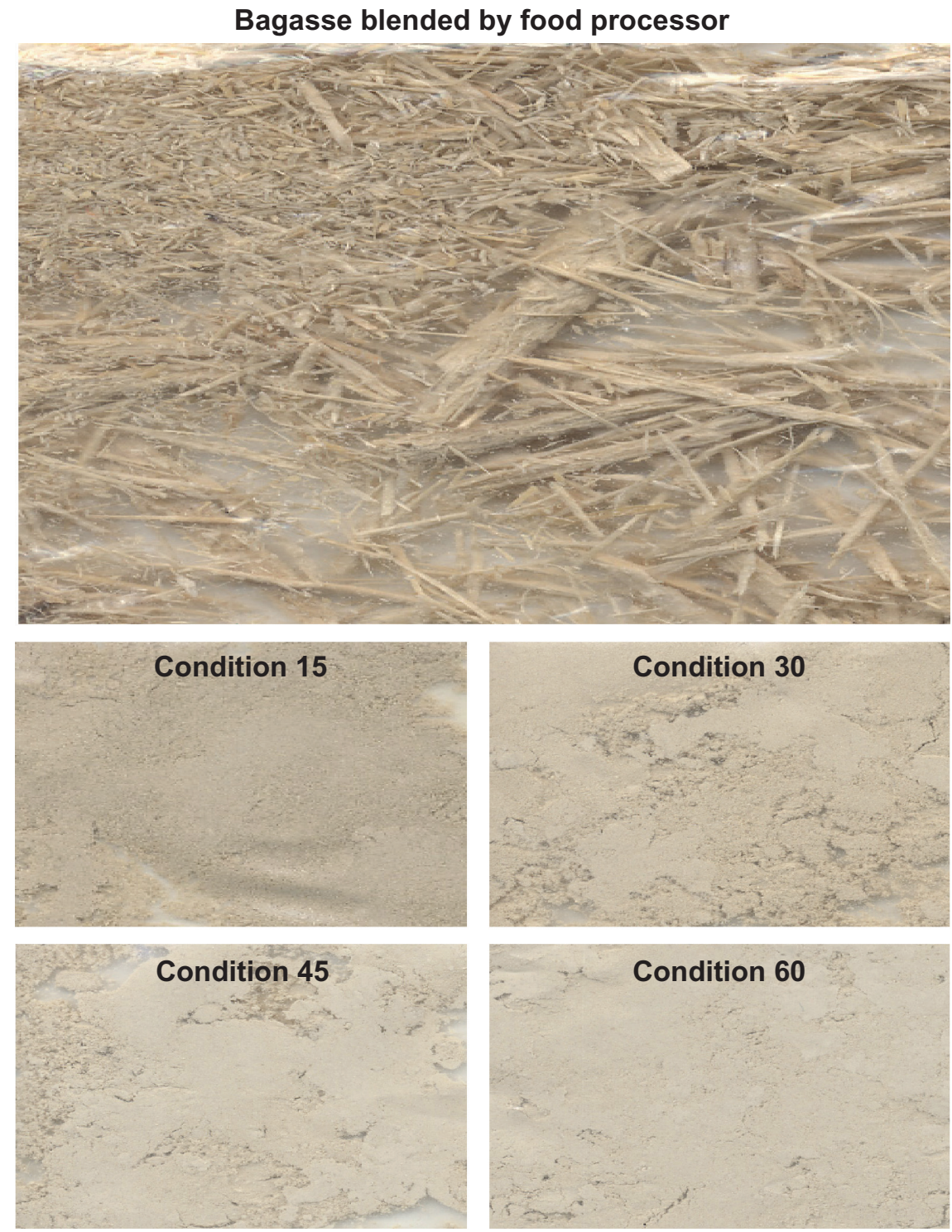

Figure SI Sugar cane fiber processing conditions.

Notes: After blending, a proprietary method was used to reduce the remaining components (bagasse) to nanometer-sized particles. The particle sizes of sugarcane fiber were: blended $>$ condition $15>$ condition $30>$ condition $45>$ condition 60 , in which $70 \%$ of particles were less than I $\mu \mathrm{m}$. 
A
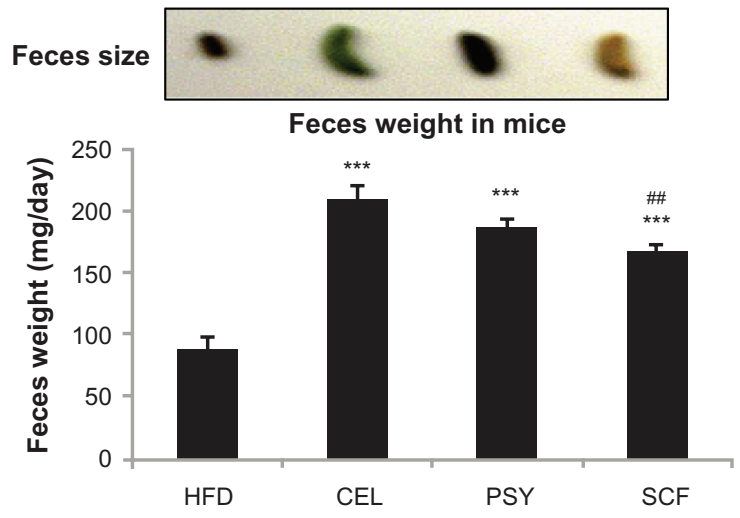

B

\section{Glycerol levels in feces of mice}

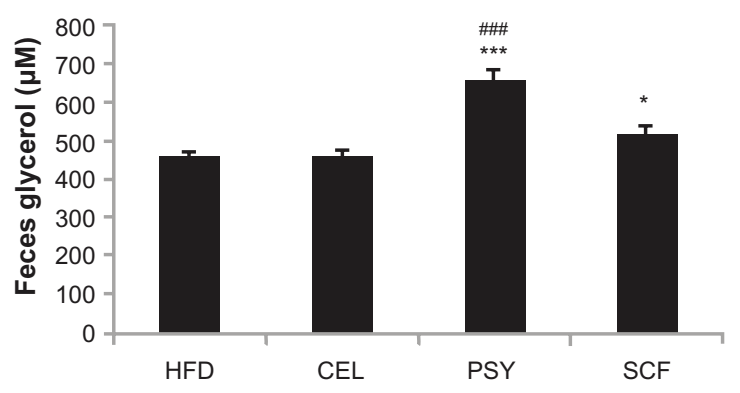

C

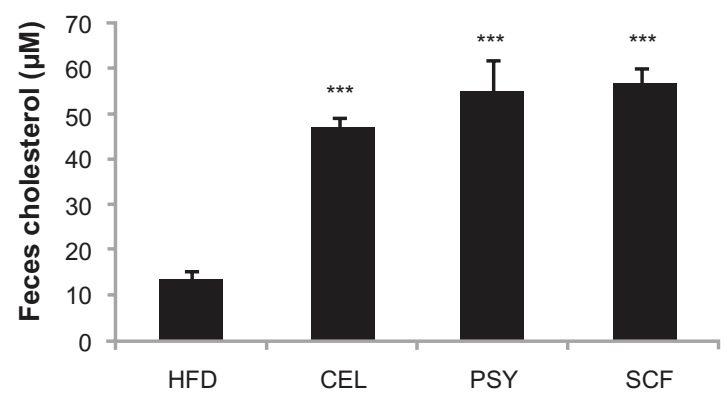

Figure S2 Feces weight and lipid contents in mice fed various dietary fibers. (A) Feces size and weight. The different colors are due to food dye. Feces were collected over a 24-hour period and weighed. (B) and (C) show the glycerol and cholesterol content of mouse feces. Lipids were extracted from feces using chloroform:methanol (I:2, $\mathrm{v} / \mathrm{v}$ ). Glycerol and cholesterol levels in the feces were determined using using a free glycerol determination kit, cat \# FG0I00 (Sidma-Aldrich, St Louis, MO) or a cholesterol quantitation kit, cat \# K603-I00 (BioVision, Milpitas, CA), respectively.

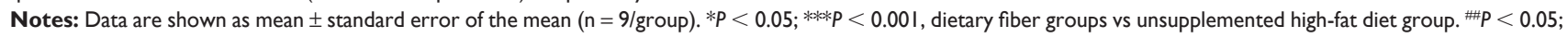
\# $<$ < 0.001 , comparison between dietary groups.

Abbreviations: CEL, cellulose; HFD, high-fat diet; PSY, psyllium; SCF, sugar cane fiber.

\section{Publish your work in this journal}

The International Journal of Nanomedicine is an international, peerreviewed journal focusing on the application of nanotechnology in diagnostics, therapeutics, and drug delivery systems throughout the biomedical field. This journal is indexed on PubMed Central, MedLine, CAS, SciSearch $\AA$, Current Contents ${ }^{\circledR} /$ Clinical Medicine,
Journal Citation Reports/Science Edition, EMBase, Scopus and the Elsevier Bibliographic databases. The manuscript management system is completely online and includes a very quick and fair peer-review system, which is all easy to use. Visit http://www.dovepress.com/ testimonials.php to read real quotes from published authors. 